\title{
Cytomorphometric analysis of oral mucosal cells in diabetic patients
}

\author{
Ramanand O V1, Shyam Prasad Reddy $\mathrm{D}^{2}$, \\ Madhusudhan Rao $\mathrm{T}^{3}$, Keerthi $\mathrm{M}^{4}$, Ajay Prakash $\mathrm{P}^{5}$
}

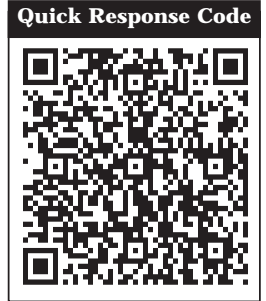

\section{doi: $10.5866 / 2014.641659$}

${ }^{1}$ Senior Lecturer

Department of Oral Pathology,

S.V.S Institute of Dental Sciences,

Mahbubnagar-509002, Telangana State.

${ }^{2 \& 4}$ Senior Lecturer

Department of Oral Pathology,

Kamineni Institute of Dental Sciences,

Narketpally, Nalgonda, Telangana State.

${ }^{3}$ Reader

Department of Oral Pathology,

Lenora Institute of Dental Sciences,

NH-16, Rajanagaram, Rajahmundry - 533294

East Godavari (Dist.), Andhra Pradesh

${ }^{5}$ Professor and Head

Department of Oral Pathology,

Mallareddy Dental College for Women's,

Sy No. 138, Suraram Main Road,

GHMC Quthbullapur, J eedimetla,

Hyderabad - 500 055, Telangana State.

\section{Article Info:}

Received: J uly 11, 2014

Review Completed: August 10, 2014

Accepted: November 9, 2014

Available Online: J anuary, 2015 (www.nacd.in)

(C) NAD, 2015 - All rights reserved

\section{Email for correspondence:}

ovr.1985@gmail.com

\section{ABSTRACT:}

Background: Diabetes is growing and massive silent epidemic that has potential to cripple heal th services affecting various tissues of the body induding oral cavity. It has been shown that it may also cause various changes in the cells of oral mucosa such as increased nuclear diameter, increased nuclear-cytoplasmic ratio, decreased cell size etc. The present study was planned for evaluation of cellular and nuclear changes seen in diabetic patients using cytomorphometric analysis of oral mucosa.

Objectives: To analyze oral mucosal smears in Type I and Type II diabetic patients cytomorphometrically and compare with the healthy normal controls.

Materials and method: The study was carried out in 45 known Type I Diabetic patients, 45 known Type II Diabetic patients and 45 normal healthy individuals. Oral mucosal smears were prepared, subjected to papanicolaou stain and assessed for cytomorphometrical changes using image analysis software (image pro insight version 8.0) and the results were statistically analyzed using SPSS software.

Results: There was statistically significant increase in the mean value of maximum diameter of the nucleus, minimum diameter of nudeus, perimeter of nucleus, area of the nucleus, mean value of maximum diameter of cell, minimum diameter of cell, perimeter of cell, area of cell in both the groups when compared healthy individuals.

Conclusion: Exfoliative cytology can be used as an adjunctive tool to aid in the diagnosis of diabetes mellitus.

Key words: Type I Diabetes, Type II Diabetes, Exfoliative Cytology, Cytomorphometry.

\section{INTRODUCTION}

Diabetes Mellitus (DM) is a metabolic disorder of multiple etiologies characterized by chronic hyperglycemia with disturbances of carbohydrate, fat and protein metabolism resulting from defects in insulin secretion, insulin action, or both. The chronic hyperglycemia of Diabetes is associated with long term damage, dysfunction and failure of various organs, especially the eyes, kidneys, nerves, heart and blood vessels and oral cavity. ${ }^{1}$

\section{Indian Journal of Dental AdVAncements Journal homepage: www. nacd. in}


It is the most common non-communicable disease worldwide and the fourth to fifth leading cause of death in developed countries. The global figure of people with diabetes is set to rise from the current estimate of 150 million to 220 million in 2010 and upto 300 million in 2025. Developing countries such as India had the maximum increases in the last few years. It has been estimated that by the year 2025, India will have the largest number of diabetic subjects in the world. ${ }^{2}$

Several abnormalities and complications have been reported to be associated with diabetes mellitus. The classical symptoms include polydypsia, polyphagia, polyuria, fatigue, weakness, irritability, weight loss and pruritis. The complications related to oral cavity mainly includes periodontal diseases (Periodontitis and gingivitis), salivary dysfunction leading to a reduction in salivary flow and changes in saliva composition, and taste dysfunction, oral fungal and bacterial infections. ${ }^{3}$ Different clinical and paraclinical techniques are available for detection of oral mucosal changes. Incisional or Excisional biopsy is the most reliable technique for definitive diagnosis of diseases occurring in oral mucosa. ${ }^{4}$ Exfoliative cytology a diagnostic tool that has got an immense value in mass screening programs of high-risk adult population. Exfoliative cytology is a relatively easy, simple and noninvasive, painless, economical clinical technique which has the potential to be devel oped as a routine investigation for screening of diabetes mellitus. It can be done chair-side during routine dental examination. ${ }^{5}$

The use of oral exfoliative cytology in the past was limited due to the subjective nature of its interpretations and high false negative results. A quick browsing through the search engines reveals that a number of special procedure can be performed on exfoliated cells like I mmunohistochemistry (IHC), image analysis etc which demonstrates the scope of this branch in disease diagnosis. ${ }^{6}$

The technique of image analysis offer an opportunity to quantify the nuclear and cell changes associated with abnormal cell and provides an objective basis for differentiating from normal cells. Over all, these results have shown that the quantitative histomor phometric methods can detect features that may be overlooked by routine histopathological examination. ${ }^{7}$
The present study was designed to evaluate oral mucosal smears in type I and type II diabetic patients' cytomorphometrically and compare with the healthy normal controls.

\section{MATERIAL AND METHODS}

The present study was carried out in 90 Diabetic patients (study group), 45 patients with Type I Diabetes and 45 patients with Type II Diabetes with a mean history of 3-6 years of age group 30-75years with fasting blood glucose value of $>126 \mathrm{mg} / \mathrm{dl}$ were selected. The control group comprised of 45 normal healthy individuals, age and sex matched subjects, who had no history of diabetes with clinically normal mucosa. All the reference subjects were free from any concomitant systemic diseases. An informed consent is obtained from both the study groups and control groups. A predetermined case sheet is used to record the data, history, clinical findings and the blood- glucose values.

Individuals with smoking, tobacco chewing habits, habitual alcohol intake, and presence of any oral sepsis and presence of other systemic diseases (lesions, infections) were excluded from the study.

All the oral smears were prepared using wooden stick with a gentle scrapping motion from the clinically appearing normal healthy buccal mucosa and were stained using papanicolaou stain.

PAP stained smears were observed under binocular compound microscope and the cells were selected by systematic sampling in a step wise manner, moving from left to right and then down and across in order to avoid measuring the same cells again. Only cells that were fully included in the field of vision and 10 clearly defined cellular and nuclear outlines were selected. Cells that were clumped, overlapped or folded were excluded for the analysis. Averages of 10 clearly defined cells were selected in each case which were projected on to the monitor through the camera at 40X magnification and images were captured. The captured images of individual cells were subjected to Morphometric analysis using image analysis system (I mage Pro Insight Version 8.0).

For the measurement of the cell, the function 'Measurement mode' was selected from the main menu, where the icon-specifying 'Polygon' was enabled to analyze the region of interest. Using the 
mouse, the cursor is placed at a point on the perimeter of the image of the cell on the screen and traced along the border of cell. This outline of the region of interest calculated the number of pixels in the cell image and displayed the area in square microns. Similarly the perimeter, area and diameter of nucleus and cell were determined (Figure 1 and 2).

All the above parameters were calculated by the I mage analysis software thereby considerably reducing the subjective error and the measurements were saved in Microsoft excel for further statistical analysis.

SPSS was used for statistical analysis. The significance of the results obtained from the control and study groups werestatistically analyzed by one way Anova test. The $p$-value $<0.05$ was considered to be statistically significant. Mean of the study group and controls was also determined.

\section{RESULTS:}

The mean values of all the study parameters were tabulated (Table 1).The mean value of maximum diameter of the nucleus of both the study groups were increased compared to controls and was statistically significant ( $p$-value 0.000). The mean value of minimum diameter of the nucleus of both the groups were increased compared to controls and was statistically significant ( $p$ - value 0.057 ). The mean value of perimeter of the nucleus of both the groups were increased compared to controls and was statistically significant ( $p$ - value 0.000 ). The mean value of area of the nucleus of both the groups were increased compared to controls and was statistically significant ( $p$-value 0.000) (Table2). The mean value of maximum diameter of the cell of both the groups were increased compared to controls and was statistically significant ( $p$-value 0.000). The mean value of minimum diameter of the cell of both the groups were increased compared to controls and was statistically significant ( $p$-value 0.000). The mean value of perimeter of the cell of both the groups were increased compared to controls and was statistically significant ( $p$ - value 0.000). The mean value of area of the cell of both the groups were increased compared to controls and was statistically significant ( $p$ - value 0.000) (Table 3).

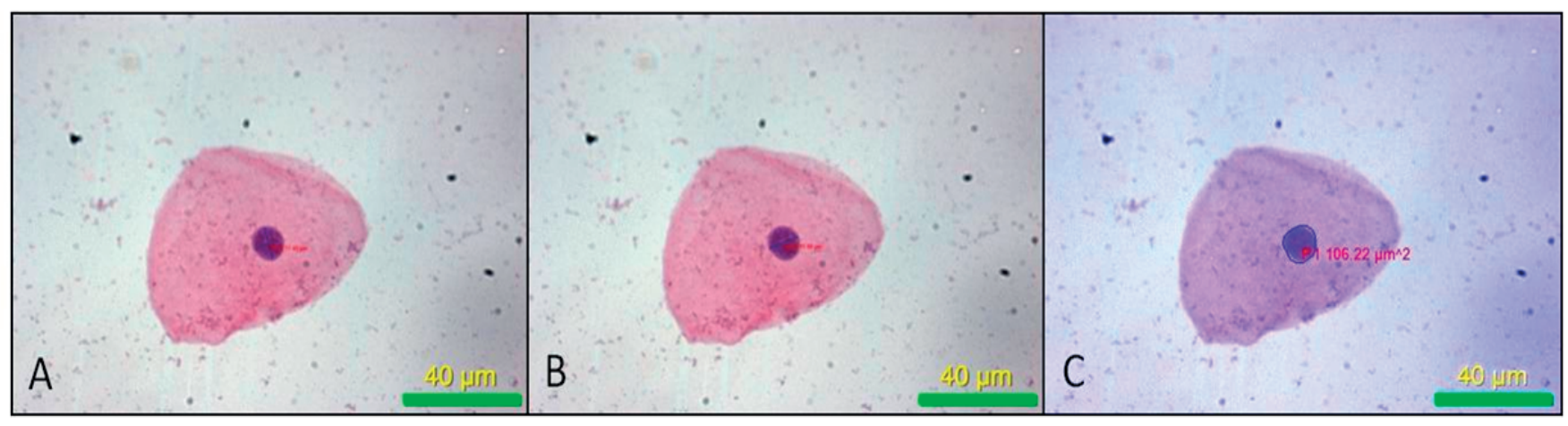

Figure 1: (A) Maximum diameter of the nucleus, (B) Minimum diameter of the nucleus, (C) Area of the nucleus determined by the image analysis software.

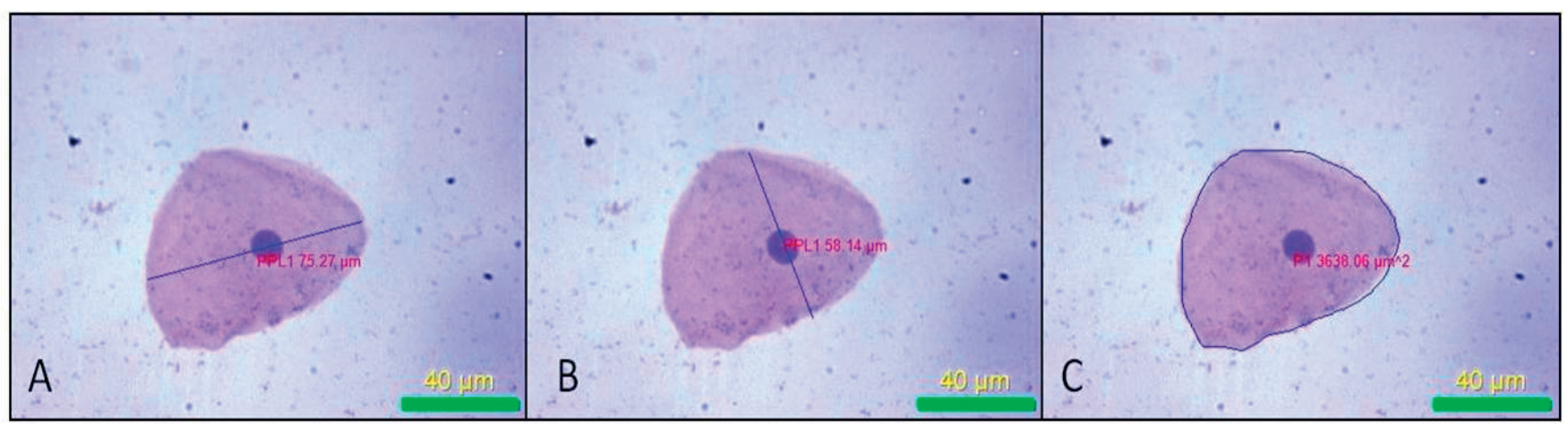

Figure 2: (A) Maximum diameter of the cell, (B) Minimum diameter of the cell,

(C) Area of the cell determined by the image analysis software. 
Table 1: Results showing mean values.

\begin{tabular}{lcccccccc} 
& Max D N & Min D N & PN & AN & Max D C & Min D C & PC & AC \\
Control & 10.019 & 6.055 & 26.832 & 48.512 & 54.961 & 34.735 & 152.16 & 1551.9 \\
& $\mu \mathrm{m}$ & $\mu \mathrm{m}$ & $\mu \mathrm{m}$ & $\mu \mathrm{m}^{2}$ & $\mu \mathrm{m}$ & $\mu \mathrm{m}$ & $\mu \mathrm{m}$ & $\mathrm{m}^{2}$ \\
\hline Type I & 12.035 & 7.879 & 33.427 & 76.925 & 72.608 & 47.756 & 209.59 & 2854.4 \\
& $\mu \mathrm{m}$ & $\mu \mathrm{m}$ & $\mu \mathrm{m}$ & $\mu \mathrm{m}^{2}$ & $\mu \mathrm{m}$ & $\mu \mathrm{m}$ & $\mu \mathrm{m}$ & $\mu \mathrm{m}^{2}$ \\
\hline Type II & 12.016 & 9.571 & 33.147 & 75.928 & 73.664 & 47.032 & 206.81 & 2792.1 \\
& $\mu \mathrm{m}$ & $\mu \mathrm{m}$ & $\mu \mathrm{m}$ & $\mu \mathrm{m}^{2}$ & $\mu \mathrm{m}$ & $\mu \mathrm{m}$ & $\mu \mathrm{m}$ & $\mathrm{m}^{2}$ \\
\hline
\end{tabular}

*MaxDN-maximum diameter of nucleus, MinDN-minimum diameter of nucleus, PN-perimeter of nucleus, AN-area of nucleus, MaxDC-maximum diameter of cell, MinDC-minimum diameter of cell, PC-perimeter of cell, AC-area of cell.

Table 2: One way ANOVA table for study parameters of nucleus variable between the groups.

\begin{tabular}{llrrrrr} 
& & Sum of Squares & \multicolumn{1}{c}{ df } & Mean Square & F & Sig. \\
Max.N & Between Groups & 1207.444 & 2 & 603.722 & 135.408 & 0.000 \\
\hline & Within Groups & 6005.639 & 1347 & 4.459 & & \\
\hline Min.N & Total & $\mathbf{7 2 1 3 . 0 8 2}$ & $\mathbf{1 3 4 9}$ & & & .057 \\
\hline & Between Groups & 2783.524 & 2 & 1391.762 & 2.872 & \\
\hline & Within Groups & 652749.395 & 1347 & 484.595 & & \\
\hline PN & Total & $\mathbf{6 5 5 5 3 2 . 9 1 8}$ & $\mathbf{1 3 4 9}$ & & & \\
\hline & Between Groups & 12566.662 & 2 & 6283.331 & 188.638 & \\
\hline & Within Groups & 44867.121 & 1347 & 33.309 & & .000 \\
\hline AN & Total & $\mathbf{5 7 4 3 3 . 7 8 3}$ & $\mathbf{1 3 4 9}$ & & & \\
\hline & Between Groups & 233989.318 & 2 & 116994.659 & 186.456 & \\
\hline
\end{tabular}

*MaxDN-maximum diameter of nucleus, MinN-minimum diameter of nucleus, PN-perimeter of nucleus, AN-area of nucleus.

Table 3: One way ANOVA table for study parameters of cell variable between the groups

\begin{tabular}{llrrrrr} 
& & Sum of Squares & \multicolumn{1}{c}{ df } & Mean Square & F & Sig. \\
Max CD & Between Groups & 99354.818 & 2 & 49677.409 & 266.858 & .000 \\
\hline & Within Groups & 250752.638 & 1347 & 186.156 & & \\
\hline Min C D & Total & $\mathbf{3 5 0 1 0 7 . 4 5 6}$ & $\mathbf{1 3 4 9}$ & & & .000 \\
\hline & Between Groups & 48192.792 & 2 & 24096.396 & 220.284 & \\
\hline & Within Groups & 147345.619 & 1347 & 109.388 & & \\
\hline PC & Total & $\mathbf{1 9 5 5 3 8 . 4 1 1}$ & $\mathbf{1 3 4 9}$ & & & \\
\hline & Between Groups & 943664.644 & 2 & 471832.322 & 124.974 & .000 \\
\hline & Within Groups & 5085509.021 & 1347 & 3775.434 & & .000 \\
\hline AC & Total & $\mathbf{6 0 2 9 1 7 3 . 6 6 5}$ & $\mathbf{1 3 4 9}$ & & & \\
\hline & Between Groups & $4.857 \mathrm{E} 8$ & 2 & $2.429 \mathrm{E} 8$ & 267.531 \\
\hline
\end{tabular}

*Max CD-maximum diameter of cell, Min CD-minimum diameter of cell, PC-perimeter of cell, AC-area of cell. 


\section{DISCUSSION:}

Diabetes is growing and massivesilent epidemic that has potential to cripple health services in all parts of the world. It is the disease that affects various tissues of the body, including oral cavity. Several studies suggest a higher prevalence and severity of pathologies in oral tissues of diabetic patients like Gingivitis, Periodontitis, Candidiasis and other opportunistic infections. It has been shown that it may also cause various changes in the cells of oral mucosa such as increased nuclear diameter, increased nuclear-cytoplasmic ratio, decreased cell size etc. The present study was planned for evaluation of cellular and nuclear changes seen in diabetic patients using cytomorphometric analysis of oral mucosa.

In the present study the results showed that there was an significant increase in the mean values of maximum diameter ( $p$ - value 0.000$)$, minimum diameter $(p$ - value 0.000$)$, area ( $p$ - value 0.000$)$ and perimeter ( $p$ - value 0.000$)$ of the nucleus in type I and type II diabetic patients when compared to normal healthy individuals, which could be due to increased supply of glucose to thetissues, favoring growth of the cell that is characterized by the prominent large nucleus and concomitant increase in the diameter of the nucleus. ${ }^{8,9}$

There was also significant increase maximum diameter ( $p$ - value 0.000), minimum diameter ( $p$ value 0.000$)$, area ( $p$ - value 0.000$)$ and perimeter ( $p$ - value 0.000 ) of the cell in typel and typell diabetic patients when compared to normal healthy individuals which could be due to increase in the glucose level that enhances the protein synthesis and cell size resulting in concomitant increase in the diameter of the cell. ${ }^{\mathbf{8}, 9}$ The present study was in concordance to several other studies in literature like J ajarm HH et al, Suvarna $\mathrm{M}$ et al. ${ }^{4,8}$

The observation in the present study has revealed that there was increase in the maximum and minimum diameter of cell and nucleus, area and perimeter of the cell and nucleus respectively in diabetic groups when compared to controls, thus stating that these alterations in the cellular pattern of the oral mucosal cells in diabetic patients provide health professionals with another diagnostic tool for the verification of clinical diabetes.

\section{CONCLUSION:}

The early changes in the oral cavity due to any chronic disease can beascertained through cytology, more so through cytomorphometry. Exfoliative cytology is a moderate, straight forward and noninvasive technique compared to conventional examination. Cytomorphometric analysis of exfoliated cells can be established as a non-invasive diagnostic marker for diabetes mellitus. The results associated with clinical observations suggest that diabetes can produce morphologic and functional alterations in oral epithelial cells, detectable by microscopic and cytomorphometric analysis that can be used in the diagnosis of the disease. The present study showed a significant increase in the cell and nucleus size in diabetic patients. Further studies with greater sample size and comparison to other conditions causing similar cytomorphometric changes are needed to determine the predictive value of this method.

\section{REFERENCES:}

1. Christopher Haslett, Chilvers ER, Edwin R Chilvers, J ohn A.A. Hunter, Nicholas A Boon. Davidson's Principles and practice of medicine. 18th edition, Great Britain: ELBS with Churchill Livingstone; 2000:472.

2. Ann Marie Lynge Pederson. Diabetes Mellitus and Related Oral Manifestations. Oral Biosci Med 2004; 1:229-248.

3. Anthony T. Vernillo. Dental considerations for thetreatment of patients with Diabetes mellitus. J Am Dent Assoc 2003; 134(I):24-33.

4. J ajarm HH, Mohtasham N, Moshaverinia M, Rangiani A. Evaluation of oral mucosa epithelium in type II Diabetic patients by an exfoliative cytology method. J Oral Sci 2008; 50(3):335-340.

5. Ban Tawfeek Shareef, Kok Teong Ang, Venkatesh Ramasamy Naik. Qualitative and quantitative exfoliative cytology of normal oral mucosa in type II Diabetic patients. Med Oral Patol Oral Cir Bucal 2008; 13(11):693-696.

6. Sivapathasundharam B, Kalasagar M. Yet another article on exfoliative cytology. J Oral Maxillofac Pathol 2004; 8:5457.

7. Smitha T, Sharada P, Girish HC. Morphometry of the basal cell layer of oral leukoplakia and oral squamous cell carcinoma using computer-aided image analysis. J Oral Maxillofac Pathol 2011; 15:26-33.

8. Suvarna M, Anuradha C, Kumar K K, Sekhar P C, Lalith Prakash Chandra K, Ramana Reddy B V. Cytomorphometric analysis of exfoliative buccal cells in type II diabetic patients. J NTR Univ Health Sci 2012; 1:33-37.

9. Liyu Wu, Rik Derynck. Essential role of TGF-â signaling in glucose-induced cell Hypertrophy. Dev Cell 2009; 17(1):3548. 